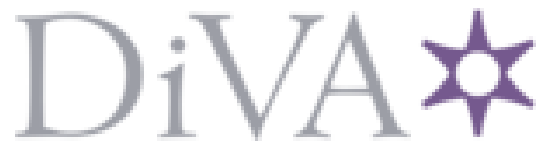

http://www.diva-portal.org

This is the published version of a paper presented at 11th ISES EuroSun Conference, OCT 11-14, 2016,Palma, SPAIN.

Citation for the original published paper:

Sommerfeldt, N. (2017)

SOLAR PV FOR SWEDISH PROSUMERS - A COMPREHENSIVE TECHNOECONOMIC ANALYSIS

In: Martinez, V Gonzalez, J (ed.), PROCEEDINGS OF THE 11TH ISES EUROSUN 2016 CONFERENCE (pp. 1339-1347). International Solar Energy Society https://doi.org/10.18086/eurosun.2016.08.01

N.B. When citing this work, cite the original published paper.

Permanent link to this version:

http://urn.kb.se/resolve?urn=urn:nbn:se:kth:diva-243628 


\title{
SOLAR PV FOR SWEDISH PROSUMERS - A COMPREHENSIVE TECHNO-ECONOMIC ANALYSIS
}

\author{
Nelson Sommerfeldt \\ KTH Royal Institute of Technology, Stockholm, Sweden \\ nelson.sommerfeldt@energy.kth.se
}

\begin{abstract}
Like many countries around the world, Sweden is experiencing an exponential growth in PV installations, driven largely by building mounted systems. As prosumers become significant actors in the electricity market, questions about how to integrate them technically, economically, and politically are becoming more critical. A recently concluded, three-year research effort dedicated to the techno-economic analysis of PV prosumers has identified some of the major challenges for multi-family housing owners in designing PV systems in light of uncertainty in the market and policies. This paper highlights the primary results and conclusions from the project, including; PV system sizing, strategies for electricity metering to maximize revenues, a Monte Carlo analysis to understand market and policy risks, and several case studies. The overall conclusion is that PV installations can be a profitable investment in Swedish multi-family houses, however it is important to have a roof with good solar resources, a well designed and installed system, and to capture as many available economic support programs as possible. While primarily focused on multi-family houses, much of this work can be used as a practical guide for many Swedish prosumers towards developing practical systems integration solutions and increasing renewable energy usage in buildings.
\end{abstract}

Keywords: Solar PV, Techno-economic, Monte Carlo analysis, Systems integration, Self-consumption

\section{Introduction}

The continued reduction in the cost of solar photovoltaics (PV) is making it increasingly easier for building owners to turn their properties into small scale, renewable energy power plants. These new actors in the energy system are transitioning from being solely consumers to both consumers and producers, often called prosumers. As subsidies continue to be reduced in parallel with reduced costs, prosumers will increasingly be subject to market conditions which will likely come with increased risk, particularly in the deregulated markets commonly found in Europe.

The PV market in Sweden is often overlooked given its small size, however the trend has been towards exponential growth (Lindahl, 2015). Solar PV is only $0.1 \%$ of total electricity generation, but it is popular with the public and if trends continue could significantly influence the power system, particularly in buildings. The low cost of electricity but high consumption and VAT taxes make prosumers the most economically interesting installation point under the current market structure.

From the prosumer's perspective, there is considerable uncertainty both inherent in the deregulated electricity market, as well as the rapidly changing policies. When considering a PV investment, there are several economically related questions which can come to mind:

- What size should the PV system be?

- What is the chance I will make a profit on my investment?

- How have others done it?

- Are there any special considerations with regards to the building? 
There are many concerns around designing and building a PV system, and it is important to prepare and execute in the best possible way to boost the chances of profitability. For example, sufficient pre-studies to ensure good solar resources, keeping costs down, and capitalizing on available subsidies. Multi-family houses (MFH) can be particularly challenging due to the coordination of tens if not hundreds of actors (Muyingo, 2015). A recently concluded, three-year study has examined PV opportunities and risks for Swedish MFH prosumers in detail (Sommerfeldt et al., 2016). This paper is a summary of the primary results and conclusions, and covers issues regarding system sizing and electricity metering with regards to selfconsumption, market and policy risks, and case studies from some first movers in this emerging market.

\section{Background}

Multi-family housing makes up 51\% of all households in Sweden, of which $41 \%$ are resident-owned cooperatives and 59\% are corporate owned and rented to tenants (Statsitics Sweden, 2013). Building electricity usage can be split into two categories; communal and private. Communal electricity consists of HVAC, exterior and stairwell lighting, garages, and laundry rooms. Private electricity is that which is used inside of apartments. Under the European Commission's energy efficiency directive (2012/27/EU), all apartments must have individual electricity meters, however billing methods can vary. Some MFH will own the apartment meters and include electricity usage with other utilities in a monthly fee, while others will allow the apartments to have electricity contracts directly with utilities and thus have their own meter. The aggregating of meters has the advantage of only one connection point with the utility that covers the entire load of the building, thus making the MFH one large customer which can save on fixed network connection fees. Independent metering gives apartment owners the freedom to select their own electricity supplier and contract to fit their needs.

Electricity supply in Sweden is dominated by hydro and nuclear power, with wind and biomass fueled cogeneration plants making up the majority of the balance (Swedish Energy Agency, 2015). Demand peaks during the winter months due to a high fraction of electric heating. The wholesale and retail electricity markets are both deregulated. Most electricity is traded on the wholesale market, Nord Pool Spot, where it is purchased by retailers and delivered to end users. A variety of economic pressures have been placed on the nuclear industry, both in the market and by the government, which is likely to lead to the premature closure of several reactors (World Nuclear Association, 2015). Renewable energy development is primarily supported through a technology neutral quota system, where demand is set by the government and prices for green certificates are set by the market based on supply. This program has largely benefited the wind and biomass industries (Swedish Energy Agency, 2015).

The Swedish solar market is relatively small compare to many others in Europe. In 2015, $47 \mathrm{MW}_{\mathrm{p}}$ were installed resulting in a cumulative total of $127 \mathrm{MW}_{\mathrm{p}}$. Fig. 1a shows how the market has expanded rapidly in recent years, which is correlated with the rapid decline in costs (shown in Fig. 1b) and favorable financial support from the government. Solar PV systems can qualify for a 20-30\% capital rebate (depending on the owner), earn green certificates to sell on the quota market, and earn a $0.06 € / \mathrm{kWh}$ feed-in bonus on overproduction sold to the network. The future of the feed-in bonus is highly uncertain, placing emphasis on selfconsumption as a way to maximize revenues. A PV system in Sweden facing south with little shading can usually expect to produce $900-1000 \mathrm{kWh} / \mathrm{kW}_{\mathrm{p}}$.
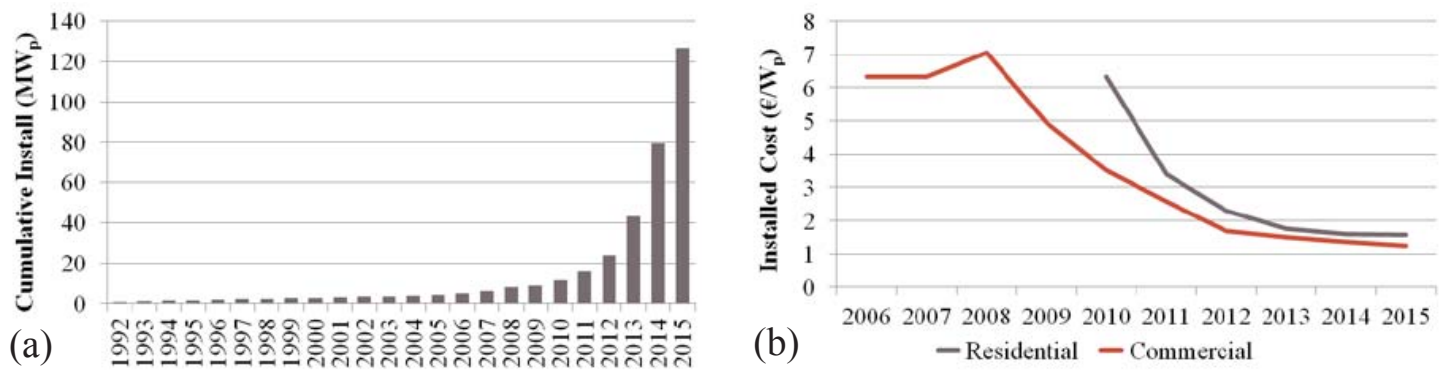

Fig. 1. Cumulative installations (left, a) and installed cost (right, b) for PV in Sweden (Lindahl, 2016) 


\section{System Sizing}

Sizing a PV system for maximum economic benefits is difficult to generalize across buildings. Differences in building load profile, system orientation, or personal economic factors can all play a role in sizing optimization. To demonstrate this, two buildings with the same annual load but significantly different load profiles are presented with a sizing sensitivity analysis. Measured building load data is used and compared to modeled PV production values from System Advisor Model (Blair et al., 2014) using TMY2 climate data from Gothenburg, Sweden. The PV systems are set facing south with a $30^{\circ}$ tilt and no shading, resulting in an annual production of $970 \mathrm{kWh} / \mathrm{kW}_{\mathrm{p}}$. The loads for each building are given in Tab. 1. with the key difference being that building one has a laundry rooms while two does not. The system sizes are increased in $1 \mathrm{~kW}_{\mathrm{p}}$ increments until reaching $100 \%$ load coverage. Net present value (NPV) is used as the key performance indicator and is reported as a function of self-consumption, demand coverage, and system size.

Tab. 1: Building parameters for sensitivity analysis

\begin{tabular}{cccc}
\hline Building & Laundry & Annual Demand & Maximum Size \\
\hline 1 & Yes & 27,490 & $28 \mathrm{~kW}_{\mathrm{p}}$ \\
2 & No & 27,974 & $29 \mathrm{~kW}_{\mathrm{p}}$ \\
\hline
\end{tabular}

The results are shown in Tab. 2 and Fig. 2 using three discount rates, where it can be seen that the discounting has a significant effect on optimal sizing of the PV systems. For example, the optimal size for building 1 moves from $11 \mathrm{~kW}_{\mathrm{p}}$ to $17 \mathrm{~kW}_{\mathrm{p}}$ to $28 \mathrm{~kW}_{\mathrm{p}}$ with a change from $3 \%$ to $1.5 \%$ to $0 \%$ discounting, respectively. The wide range signifies the difficulty in generalizing rules for all owners. Even if those owners have nearly identical buildings, they could have different discounting preferences.

Comparing the two buildings, it is clear the optimal system sizes and corresponding demand coverage varies considerably between them. This highlights the difficulty of recommending a rule of thumb for all buildings based on a single load value, even if those buildings are of the same type like a MFH. The optimal selfconsumption values are much more consistent however, which is logical since self-consumption rates scale with system size and directly affect revenues whereas demand coverage is only a sizing indicator. The curves in Fig. 2 are notably flat, with optimal size ranges being approximately $\pm 50 \%$ of the peak to remain within $5 \%$ of the maximum NPV. However, the ranges between the two buildings do not overlap.

Tab. 2. Optimal PV system sizing results comparing a MFH with and without laundry rooms

\begin{tabular}{cccccc}
\hline Building & $\begin{array}{c}\text { Discount } \\
\text { Rate }\end{array}$ & $\begin{array}{c}\text { Optimal } \\
\text { System Size }\end{array}$ & $\begin{array}{c}\text { Demand } \\
\text { Coverage }\end{array}$ & $\begin{array}{c}\text { Self- } \\
\text { Consumption }\end{array}$ & $\begin{array}{c}\text { Size Range Within } \\
\mathbf{5 \%} \text { of NPV Max. }\end{array}$ \\
\hline 1 & $3.0 \%$ & $11 \mathrm{~kW}_{\mathrm{p}}$ & $39 \%$ & $75 \%$ & $8.5-14 \mathrm{~kW}_{\mathrm{p}}$ \\
1 & $1.5 \%$ & $17 \mathrm{~kW}_{\mathrm{p}}$ & $60 \%$ & $59 \%$ & $12-23.5 \mathrm{~kW}_{\mathrm{p}}$ \\
1 & $0 \%$ & $28 \mathrm{~kW}_{\mathrm{p}}$ & $99 \%$ & $42 \%$ & $19-28 \mathrm{~kW}_{\mathrm{p}}$ \\
2 & $3.0 \%$ & $3 \mathrm{~kW}_{\mathrm{p}}$ & $10 \%$ & $75 \%$ & $2-4 \mathrm{~kW}_{\mathrm{p}}$ \\
2 & $1.5 \%$ & $4 \mathrm{~kW}_{\mathrm{p}}$ & $14 \%$ & $64 \%$ & $3-6 \mathrm{~kW}_{\mathrm{p}}$ \\
2 & $0 \%$ & $8 \mathrm{~kW}_{\mathrm{p}}$ & $28 \%$ & $39 \%$ & $5-13 \mathrm{~kW}_{\mathrm{p}}$ \\
\hline
\end{tabular}

While it is difficult to extract a hard rule of thumb, some broad guidelines can be suggested for early stage design. In MFH with laundry rooms, the PV system can be sized such that annual production is between 30 $50 \%$ of the annual demand, which will often correlate with $60-80 \%$ self-consumption. In buildings without laundry, a $15-35 \%$ ratio can be sought for similar self-consumption rates, however more care must be taken not to oversize since NPV declines more rapidly with increases in system size. In summary, before any final system decisions it is important to review hourly demand and production profiles to estimate selfconsumption. It may also be the case that the investors are more focused on goals other than economic optimization. For example, in a case where an owner wishes to maximize their solar production, they could choose to cover $70-80 \%$ of their demand and still have a positive NPV, even if it is not the maximum value. More detailed analysis can be found in the project's final report (Sommerfeldt et al., 2016). 

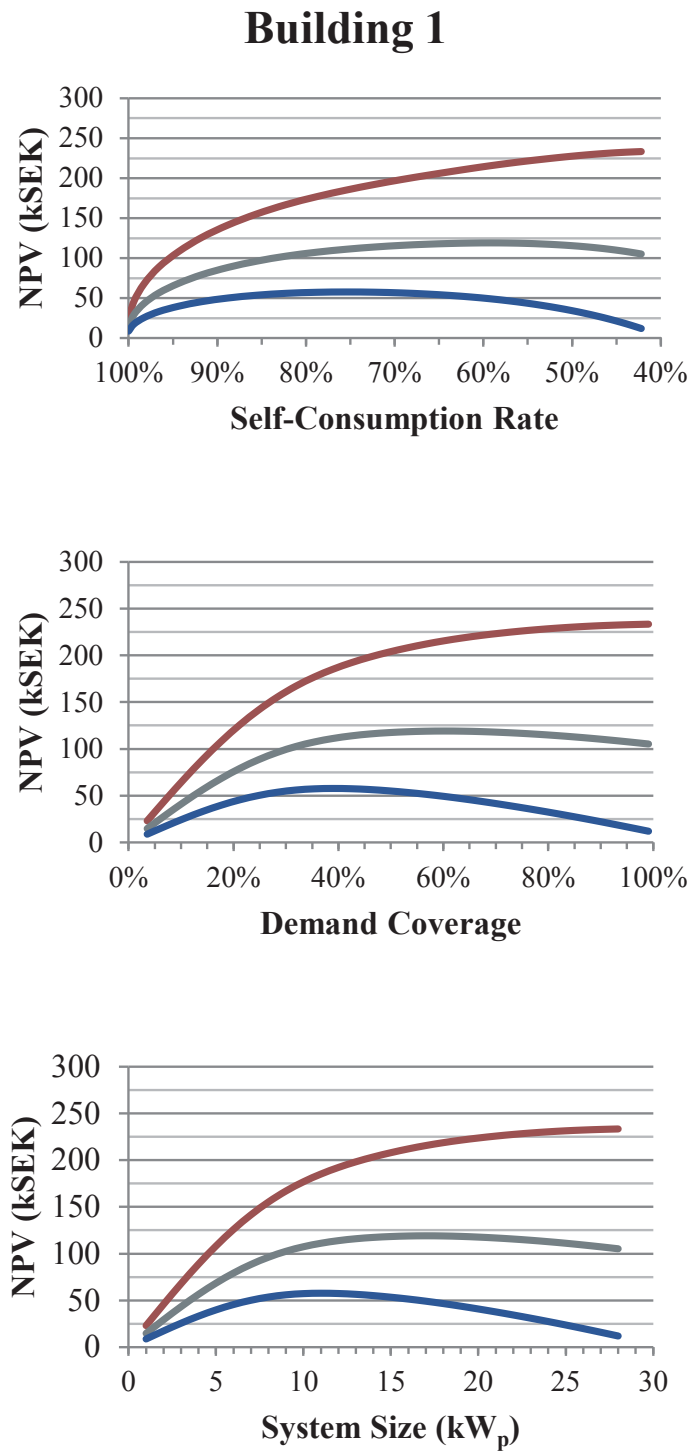

$-0 \%$ Disc. $\quad 1.5 \%$ Disc. $\quad 3 \%$ Disc.
Building 2
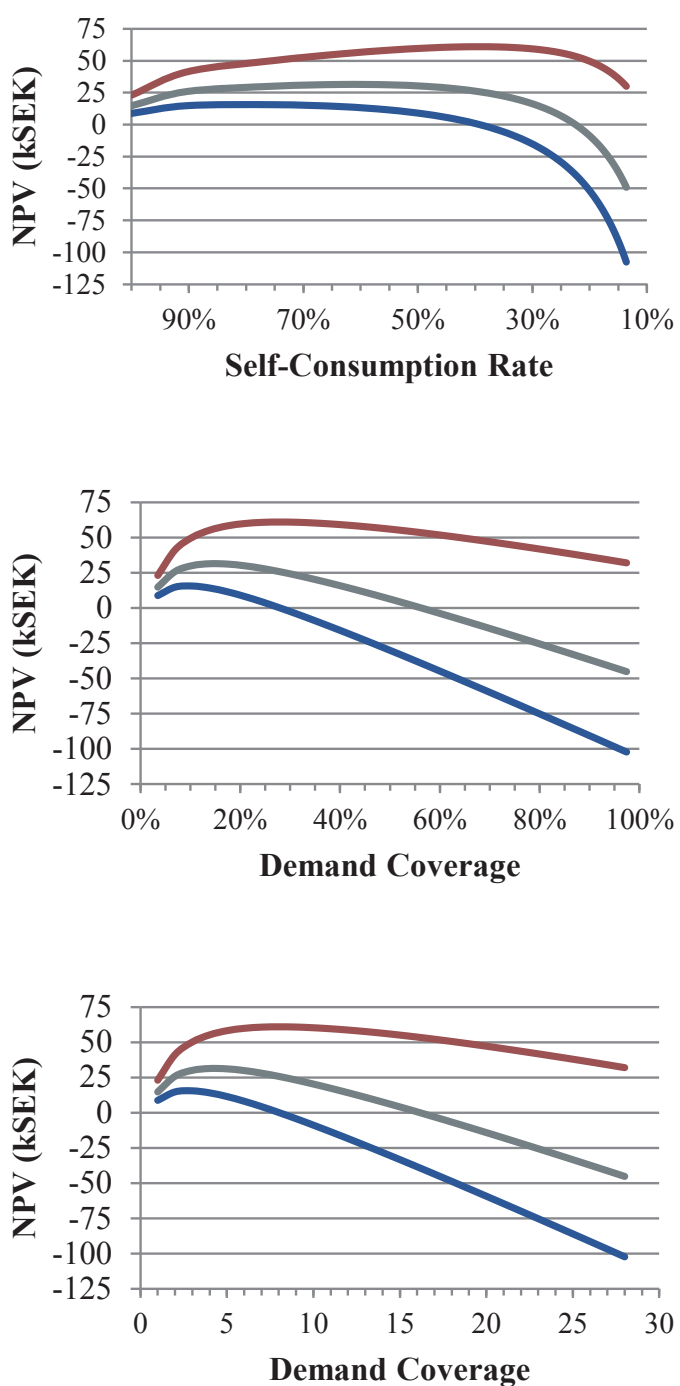

Fig. 2: PV system sizing sensitivity results for two buildings with similar demand but different load profiles

\section{Electricity Metering}

As mentioned in the background, MFH have options for how their building and apartments are metered by electric utilities; aggregated or independent. The metering configuration determines load volumes and profiles, which was shown in the previous section to impact PV system sizing and profitability due to changes in self-consumption. The effect of metering is tested for a six building housing cooperative considering four configurations, which are visualized in Fig. 3 and described as followed:

- Default: each building is metered separately and includes only communal loads

- Horizontal: all buildings are metered together and includes only communal loads

- Vertical: each building is metered separately and includes communal and apartment loads

- Combined: all buildings and all loads are combined into a single load 


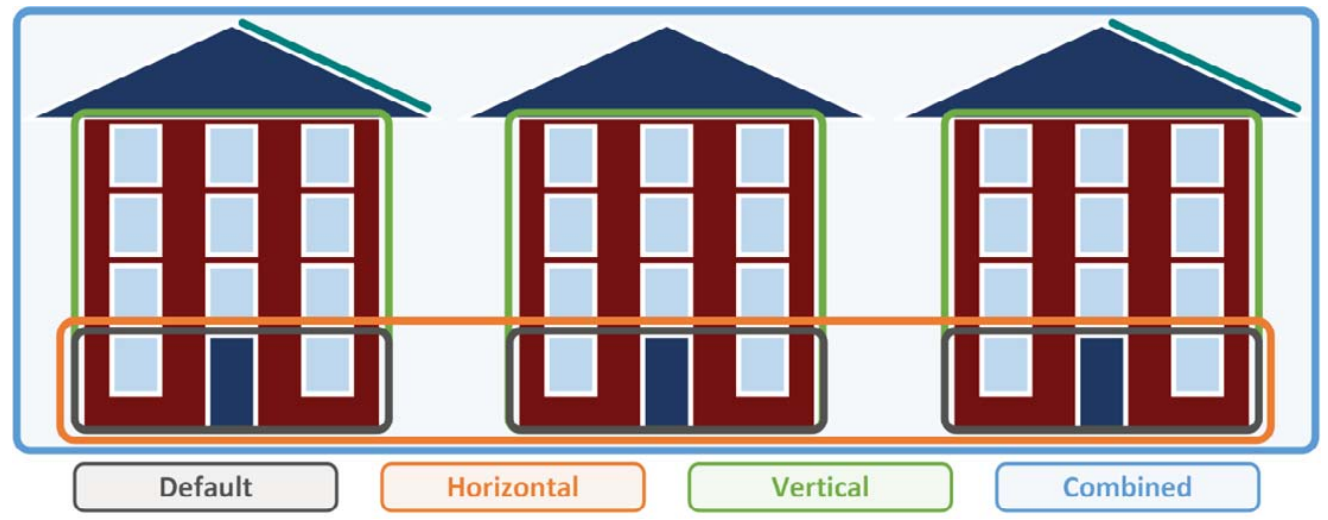

Fig. 3. Diagram of the tested metering configurations (Sommerfeldt, 2015)

Two years of measured communal load data is averaged together to create a single load curve for each of six buildings. Apartment loads are created using a Markov chain model developed by Widén and Wäckelgård

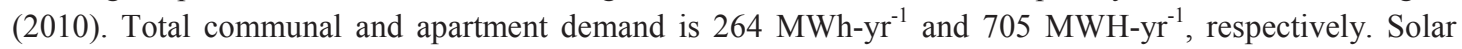
production is modeled using System Advisor Model (Blair et al., 2014) with TMY2 climate data from Gothenburg, Sweden for a PV system facing due south with a $30^{\circ}$ tilt. The buildings have identical $16 \mathrm{~kW}_{\mathrm{p}}$

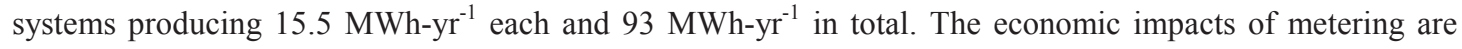
compared to the three prominent subsidies currently available in Sweden; capital rebate, green certificates, and the feed-in bonus.

Increasing self-consumption is the primary motivation for changing metering schemes, and it is found that a vertical scheme is more effective than horizontal. The default self-consumption is $60 \%$ whereas the horizontal configuration increases to $77 \%$ and the vertical to $97 \%$. This is not entirely surprising given the significantly greater load found in the apartments. When combined the self-consumption rate reaches $100 \%$. The effect on profitability is shown in Fig. 4, where NPV is shown to increase by $€ 60,000$ in the vertical configuration. This is significantly more than any of the subsidies which are $€ 44,000$ when combined (the subsidies are added cumulatively moving from left to right).

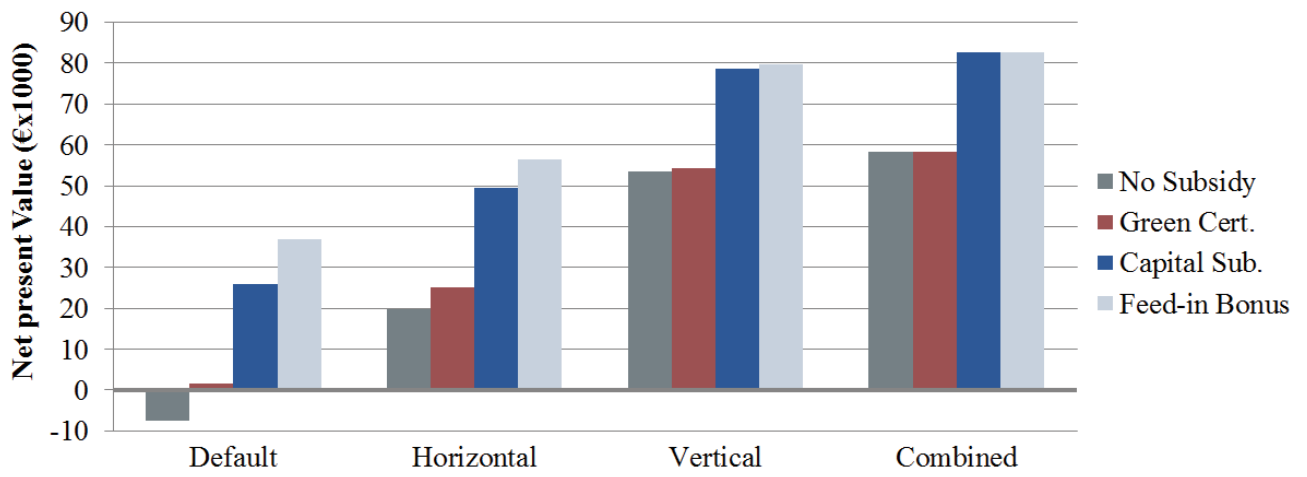

Fig. 4. Net present value of each metering scheme compared to various subsidies (Sommerfeldt, 2015)

Vertical and combined metering configurations are not entirely uncommon in Sweden due to the savings on network fees. However many MFH would need to convert, which would require the replacement of utility meters with those owned by the cooperative. The cost of this conversion would be approximately $€ 35,000$ which significantly reduces the benefit as it relates to the PV installation, but should also be compared to the saving in network fees which must be done on a case by case basis. The results also place the importance of metering in context with state subsidies. If it were easier to share generation between prosumers and consumers (i.e. removing tax and market structure barriers), then it might be possible to save on direct subsidies. Alternatively, energy service companies could see this as an opportunity to create micro-grids on housing campuses with solar PV. A more complete analysis can be found in a recent ISES Solar World Congress paper (Sommerfeldt, 2015). 


\section{Monte Carlo Analysis}

Monte Carlo analysis (MCA) is a mathematical modeling method which uses traditional performance indicators but selects inputs at random from predefined distributions to perform repeated iterations and create a distribution of results. The MCA process can be viewed like an outer layer surrounding the inner deterministic layer, as shown in Fig. 5. Presenting the results as a distribution rather than a point value is an improvement over common sensitivity analyses in that it can give the results in a way that tells the investor what is likely to happen rather than what could happen. This is particularly relevant for PV and other renewables, which are typically subject to long payback times.

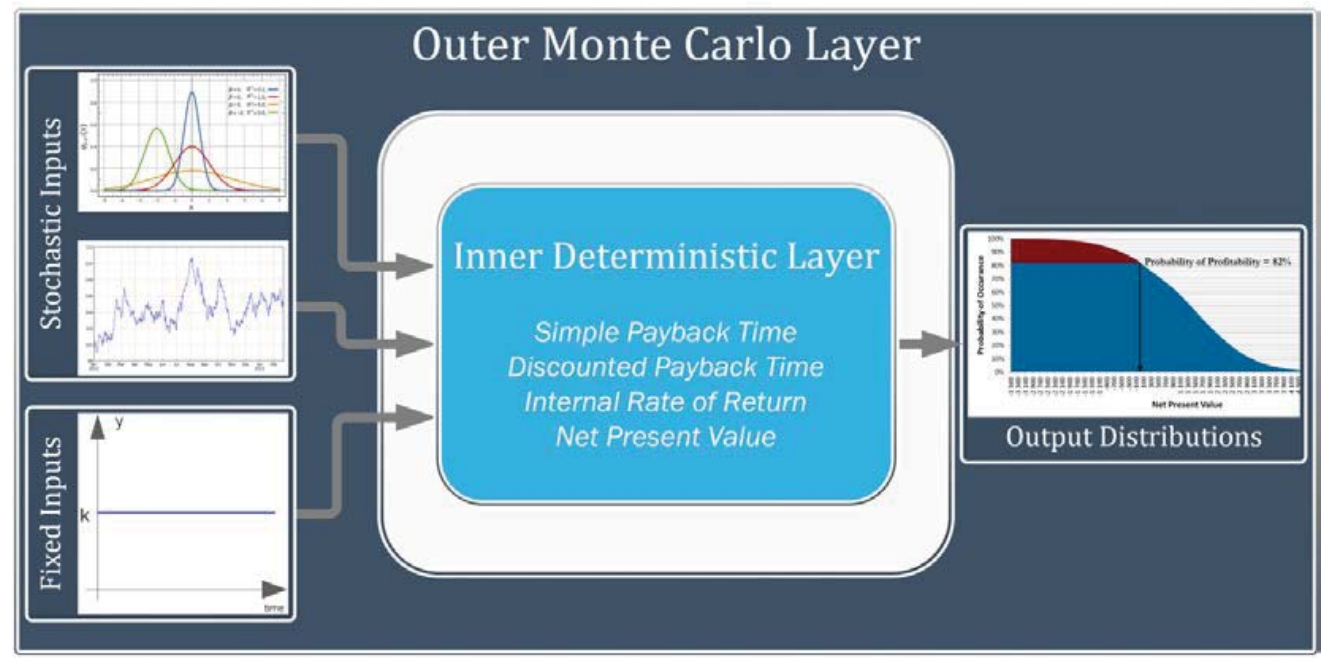

Fig. 5: Diagram of the MCA method in relation to traditional deterministic methods (Sommerfeldt and Madani, 2016)

At the core of the probabilistic method are the traditional deterministic, cost-benefit calculations based on discounted cash flows (Short et al., 1995). The outer MCA layer selects input values at random from a distribution to be fed into the deterministic models. Only the most critical factors are considered for probabilistic input, which includes electricity price, installation cost, annual generation, self-consumption rate, system lifetime, and the real discount rate. Electricity price is treated with a novel geometric Brownian motion model, while the remaining inputs are given distributions.

The output from the MCA is a distribution of NPV values. This is used to create two metrics; the probability of profitability (PoP) and probability of principle return (PPR). Profitability in this case is defined as earning the desired real discount rate (in this case a 3\% real return), and thus the PoP represents the chance that NPV will be greater than zero. PPR is found the same way, however with the discount rate at $0 \%$ and thus representing only the return of the original investment.

The case presented here is intended to be representative of the most common PV installations currently in Sweden. Nominal values are annual generation at $900 \mathrm{kWh} / \mathrm{kW}_{\mathrm{p}}$, an installation cost of $1.81 € / \mathrm{kW}_{\mathrm{p}}$, a system lifetime 30 years, and a self-consumption rate of $60 \%$. The primary subsidies (capital rebate, green certificates, and the feed-in bonus) are examined in three policy scenarios, shown in Tab. 3 , to give a practical assessment from the prosumer perspective. They are also examined separately to identify their individual impact.

Tab. 3: Policy scenario descriptions

\begin{tabular}{cccc}
\hline Scenario & Capital Rebate & Green Certificates & Feed-In Bonus \\
\hline Unsubsidized & None & None & None \\
Common Case & $15 \%$ & Overproduction & 5 Years \\
Best Case & $20 \%$ & All production & 15 Years \\
\hline
\end{tabular}


The results in Fig. 6 show that under a common case of policy support, a prosumer with a well-designed and well-oriented system has an approximately $70 \%$ chance of earning a profit. Without subsidies the probability falls to $8 \%$ and in a best case scenario there is a $97 \%$ chance of profit. Interestingly, the PPR is $100 \%$ in all cases, even without any policy support.

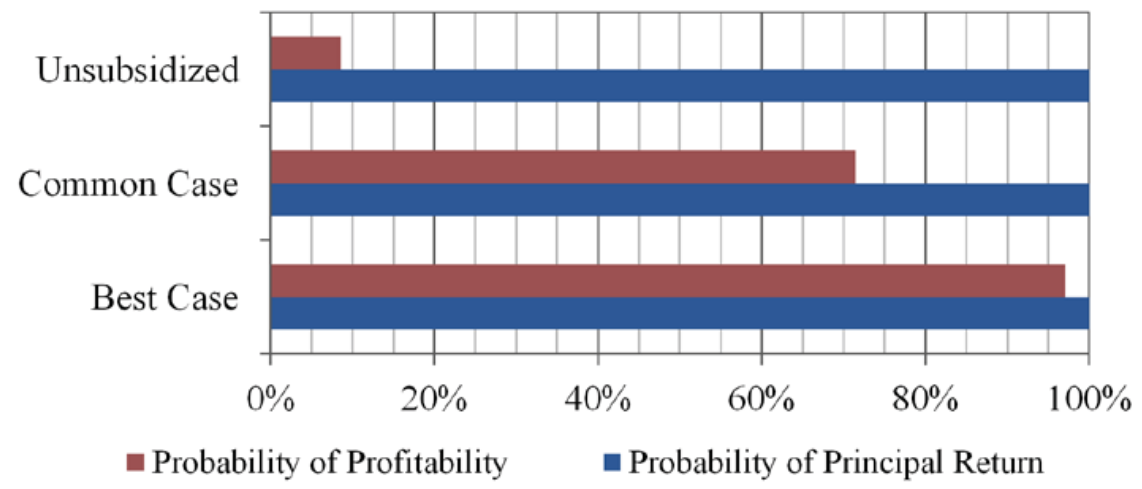

Fig. 6: Probability results for the policy scenarios (Sommerfeldt and Madani, 2016)

Comparing results from the various policies, shown in Fig. 7, indicates that the capital subsidy is the strongest tool for profitability in Sweden. The 20\% capital subsidy alone is capable of lifting the PoP from $8 \%$ to nearly $60 \%$. The feed-in bonus is the next valuable while green certificates are the least, however the feed-in bonus' future remains highly uncertain. The impact of the capital subsidy on profitability is in large part due to the immediate payment, which has no discounting applied and thus carries more value to the investor than payments extending into the future.

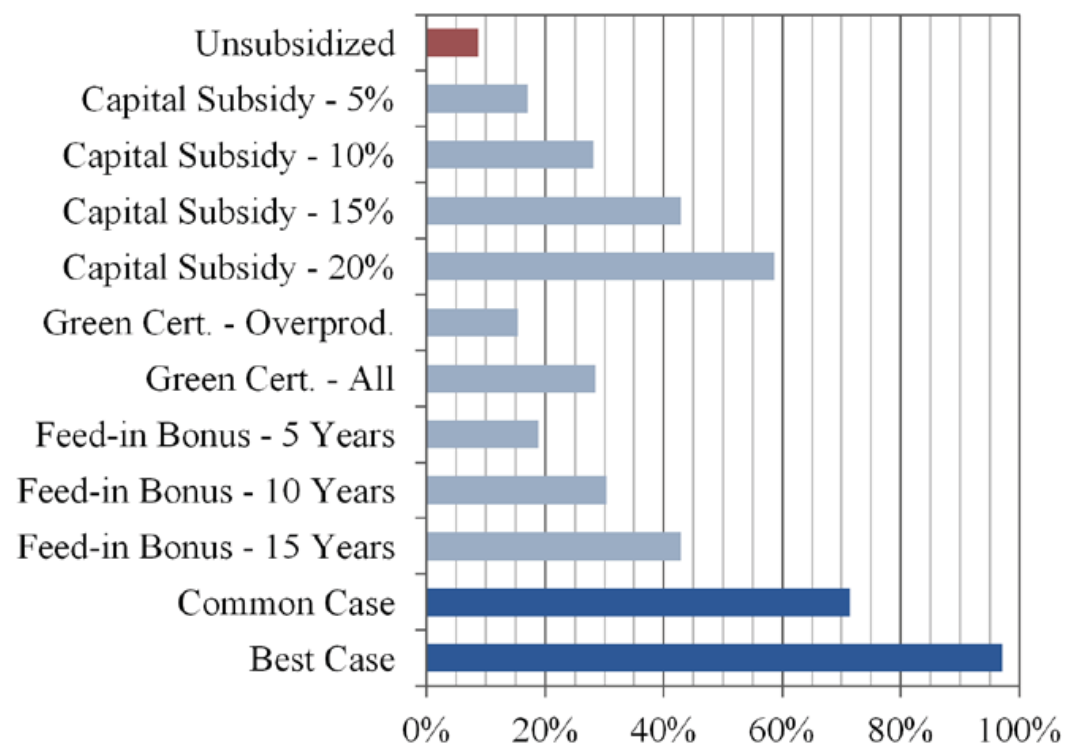

Fig. 7: PoP values for a range of subsidy levels for the most direct PV support policies (Sommerfeldt and Madani, 2016)

It is important to note that the applicability of these results are limited to the assumptions and models used, most important of these being the current market structure. There are a number of possible exogenous risks which are not easily incorporated into a single MCA which could significantly alter the probabilities presented here. These abbreviated results and further detailed analysis is presented in a recently submitted article currently under review (Sommerfeldt and Madani, 2016). 


\section{Case Studies}

Like the remainder of the Swedish market, the number of MFH installing solar PV systems is small but growing. The boards of directors from three early adopting MFH cooperatives agreed to interviews to discuss their experiences and are used as case studies to learn about the ideation, planning, execution, and conclusions about installing a PV system. The results are summarized here and a more complete description can be found in (Sommerfeldt and Muyingo, 2015).

In all cases, the motivation for installing a PV system is rooted in a desire to improve the economic position of the cooperative. This would primarily be achieved through reduced energy costs, but in some cases it was believed that the system would create a positive image for the cooperative and subsequently improve property prices. All of the cooperatives were presented with a financial analysis from an outside party prior to construction; in two cases from the contractor installing the system and in the other the economics were simply estimated without calculation. Naturally these reports indicated positive returns for their investment such that they wanted to move forward. Since the time of the original analyses, the electricity prices collapsed by $40 \%$ and significantly altered the economic outlook. In one case it is highly unlikely that they will earn a return and may even lose some principle.

The unforeseen downturn has not dissuaded the boards from considering their projects a success. This could be because economic factors are not as critical as originally claimed, or that their opinion is biased since they have little choice but to accept the installations. The boards also see their PV as positive advertisement for their community, which has been confirmed by two of the cases being given awards by the Solar Energy Association of Sweden for their pioneering efforts (Solar Energy Association of Sweden, 2015). All of the communities have received media attention in some form, which could very well result in higher property prices since the environmental awareness in Sweden is relatively high (TNS Opinion \& Social, 2014).

These cases highlight the challenges that can arise with early adopters and there is a need for improved financial assessment for PV, particularly in deregulated markets like Sweden where forecasts have a high uncertainty. However the general attitude towards PV suggests a continued increase on installations, particularly if environmental and social benefits are highlighted. As one chairman put it, "the long term sustainability of the cooperative is more important than the short term economics."

\section{Conclusions}

While the volume of the Swedish PV market is still small, awareness and interest are growing such that more and more building owners are considering becoming prosumers. The results here show that PV investments can be profitable, but without dedicated policy support the chances of earning an acceptable return are low. Even with positive investment indicators, it is important for prosumers to keep in mind that PV is a long term investment and that a well design and installed system are necessary. Policy towards prosumers is highly uncertain, however high levels of self-consumption have been identified as a good way to hedge against policy changes and maintain profitability.

From a policymaker's perspective; of the policies currently in place, the capital rebate is the most powerful and valuable to the prosumer. The receipt of the money earlier in the investment results in less discounting costs and in less uncertainty about the value. By comparison, green certificates can be earned for 15 years and have a moving price based on market conditions. Green certificates and the feed-in bonus can also act against the development of flexibility via storage or demand response. Policies should support the transition to a flexible electricity system. Therefore emphasis should be placed on the capital rebate with a long term, transparent plan for phase out that encourages stability for investing.

\section{Acknowledgements}

This research is funded by the Swedish Research Council Formas (no. 2012-256) and performed in conjunction with Riksbyggen, Sustainable Innovation, and the KTH School of Architecture and the Built Environment. 


\section{References}

Blair, N., Dobos, A.P., Freeman, J., Neises, T., Wagner, M., Ferguson, T., Gilman, P., Janzou, S., 2014. System Advisor Model, SAM 2014.1.14: General Description.

Lindahl, J., 2016. National Survey Report of PV Power Applications in Sweden 2015.

Muyingo, H., 2015. Organizational Challenges in the Adoption of Building Applied Photovoltaics in the Swedish Tenant-Owner Housing Sector. Sustainability 7, 3637-3664. doi:10.3390/su7043637

Short, W., Packey, D.J., Holt, T., 1995. A Manual for the Economic Evaluation of Energy Efficiency and Renewable Energy Technologies. Golden, CO, USA.

Solar Energy Association of Sweden, 2015. Solenergipriset [WWW Document]. URL http://www.svensksolenergi.se/omoss/solenergipriset (accessed 9.7.15).

Sommerfeldt, N., 2015. On the economic effects of metering schemes in community owned residential PV systems, in: 2015 ISES Solar World Congress. Daegu, South Korea.

Sommerfeldt, N., Madani, H., 2016. Revisiting the techno-economic analysis process for building mounted, grid-connected solar photovoltaic systems: Part Two - Application. Renew. Sustain. Energy Rev. Ms. Ref. No.: RSER-D-16-01501.

Sommerfeldt, N., Muyingo, H., 2015. Lessons in community owned PV from Swedish multi-family housing cooperatives, in: 31st European Photovoltaic Solar Energy Conference and Exhibition. Hamburg.

Sommerfeldt, N., Muyingo, H., af Klintberg, T., 2016. Photovoltaic Systems for Swedish Prosumers. KTH Royal Institute of Technology, Stockholm, Sweden.

Statsitics Sweden, 2013. Yearbook of Housing and Building Statistics 2012. Stockholm.

Swedish Energy Agency, 2015. Energy in Sweden: Facts and Figures [WWW Document]. URL http://www.energimyndigheten.se/Statistik/Energilaget1/ (accessed 9.6.15).

TNS Opinion \& Social, 2014. Climate change: Special Eurobarometer 409. European Commission.

Widén, J., Wäckelgård, E., 2010. A high-resolution stochastic model of domestic activity patterns and electricity demand. Appl. Energy 87, 1880-1892. doi:10.1016/j.apenergy.2009.11.006

World Nuclear Association, 2015. Nuclear Energy in Sweden [WWW Document]. Ctry. Profiles. URL http://www.world-nuclear.org/info/Country-Profiles/Countries-O-S/Sweden/ (accessed 9.25.15). 